(C)Carcinological Society of Japan. doi: 10.18353/crustacea.48.0_133

\title{
Habitat utilization and seasonal occurrence of Tachaea chinensis (Isopoda: Corallanidae) infesting freshwater shrimps in Lake Biwa, central Japan
}

Yuzo Ota

\begin{abstract}
Monthly quadrat sampling of freshwater shrimps infested by the corallanid isopod Tachaea chinensis was conducted in Lake Biwa, central Japan, between April 2014 and September 2015. In total, 3,222 shrimps, including 2,786 Neocaridina spp., 309 Paratya improvisa, and 127 Palaemon paucidens were collected. Individuals of $431 \mathrm{~T}$. chinensis were found from those hosts. The prevalence was $12.2 \%$ in Neocaridina spp., $5.5 \%$ in P. improvisa, and $24.4 \%$ in P. paucidens, respectively. All isopods found on hosts were immature stages and showed an annual emergence pattern; newly hatched juveniles were first sampled in August, increased the body length until May, and were not observed in June-July. To collect $T$. chinensis apart from the hosts, a cage trap filled with reed roots was put on the study site between June 2014 and September 2015. Isopods were collected in July and September. Specimens trapped in 2015 consisted of adult or premature individuals, and 39 out of 46 adult females collected were ovigerous. During an observation using snorkeling in July 2014, 29 adults were observed under stones and in withered Phragmites australis roots. Thus, T. chinensis reproduces in benthic habitats during summer. Subsequently, juveniles appear and grow via a series of molts on the hosts until the following year.
\end{abstract}

Key words: Ectoparasite, manca juvenile, Neocaridina, Phragmites australis, biphasic life cycle

\section{Introduction}

Corallanidae is an isopod family that includes approximately 80 species worldwide (Bruce \& Schotte, 2015). Corallanid isopods are temporary ectoparasites or micro-predators of fishes, shrimps, and other invertebrates in marine or freshwater habitats (Delaney, 1984, 1989). Most papers about the Corallanidae have focused on taxonomic descriptions. Owing to inadequate number of samples from the natural environment, little ecological information about corallanids has been reported in the literature.

The corallanid species Tachaea chinensis Thielemann, 1910 is well-known as an ectoparasite of freshwater shrimps and prawns in
East Asia (see Table 2 in Nagasawa et al., 2018). Tachaea chinensis infests on the carapace of freshwater shrimps and prawns (e.g., Thielemann, 1910; Shiino, 1965; Takeda et al., 2000; Hayashi, 2011; Toyota \& Seki, 2014; Nagasawa et al., 2018). Tachaea chinensis occurs on the hosts year round except for summer and early fall. Nakachi et al. (2010) briefly mentioned $T$. chinensis was not collected during June and July and that it may breed during this season. Takahashi (2015) indicated T. chinensis could not be sampled from the host shrimp Palaemon paucidens De Haan, 1844 from summer to early fall on the basis of monthly sampling of shrimps over an annual cycle. It still remains unknown what habitat $T$. chinensis uses during the months when the iso- 
pod is not found on the host.

This paper reports the seasonal occurrence of T. chinensis on the host shrimps in Lake Biwa, central Japan, and also focuses on the habitat utilization and reproduction of $T$. chinensis during the period apart from the hosts.

\section{Materials and Methods}

\section{Study site}

The Ima-gawa creek (3-4 m wide; located at $35^{\circ} 22^{\prime} 59.01^{\prime \prime} \mathrm{N}, 136^{\circ} 02^{\prime} 09.60^{\prime \prime} \mathrm{E}$, Fig. 1) was chosen as the sampling site after a preliminary investigation. The bottom of the creek is mud$\mathrm{dy}$, and the riverbank is grassy during the warmer seasons. The host shrimps often occur on or near reeds, grass or the exposed roots of trees in the water, or other similar structures. During the preliminary study, one Tachaea chinensis was observed apart from the host shrimp, resting within withered and broken roots of the reed Phragmites australis (Cav.) Trin. ex Steud.

\section{Seasonal occurrence of $T$. chinensis on the hosts}

In order to collect $T$. chinensis infesting on shrimps, two $1-\mathrm{m}^{2}$ quadrats were placed on the bottom of the creek approximately $10 \mathrm{~m}$ upstream from the creek's debouchment into Lake

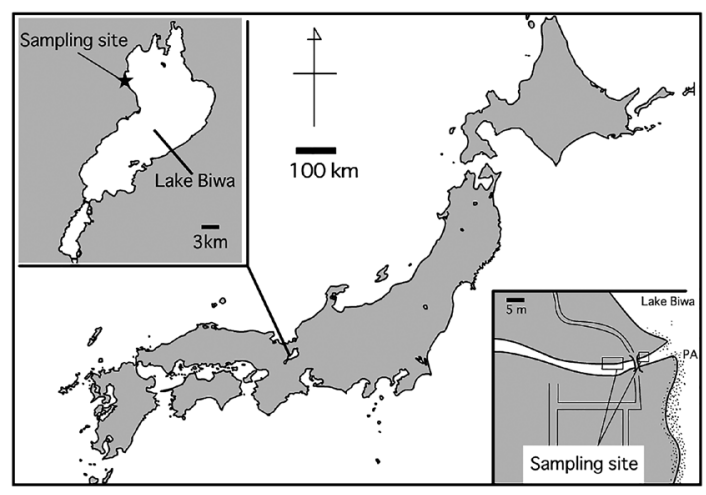

Fig. 1. Sampling sites. The host shrimps were collected using two $1 \mathrm{~m}^{2}$ quadrats from the two sampling sites. PA indicates the plant community of Phragmites australis.
Biwa (Fig. 1) between April 2014 and September 2015. In this sampling site, two quadrats were slightly moved, because grass-grown habitats where host shrimps lived were different by the season. As the host number seemed not to vary between the two quadrats, the data were combined. All shrimps were collected with using hand nets ( $2 \mathrm{~mm}$ mesh) in the quadrats. On each sampling date, the samples from the two quadrats were placed in separate buckets (15-20 L), which were then filled with water and transported to the laboratory. There, the samples were sorted out in a white tray and infected shrimp were separated from uninfected shrimps.

All shrimp samples and all T. chinensis were fixed in $70 \%$ ethanol and their body size was measured as body length, between the orbital margin contiguous to the eye and the posterior margin of telson for the host shrimps, and between the frontal border of the head and the posterior margin of the pleotelson for T. chinensis.

\section{Phragmites trap to collect $\mathrm{T}$. chinensis away from the hosts}

In order to collect $T$. chinensis apart from the hosts, withered $P$. australis roots were cut and filled in a plastic-framed cage equipped with lead weights (hereafter called "phragmites trap", $17.5 \times 10.5 \times 8.5 \mathrm{~cm}$ in size). The trap was placed on the bottom of the creek and retrieved once each month between June 2014 and September 2015 on the same day as the quadrat sampling described above. Phragmites roots were replaced each time. After retrieving the phragmites trap, phragmites roots were taken back to the laboratory and carefully dissected using forceps to collect $T$. chinensis. After that, isopod specimens were fixed in $70 \%$ ethanol and checked for sex and development of eggs in the female's brood pouch.

\section{Field observation of T. chinensis in summer}

In July 2014, T. chinensis found in withered 

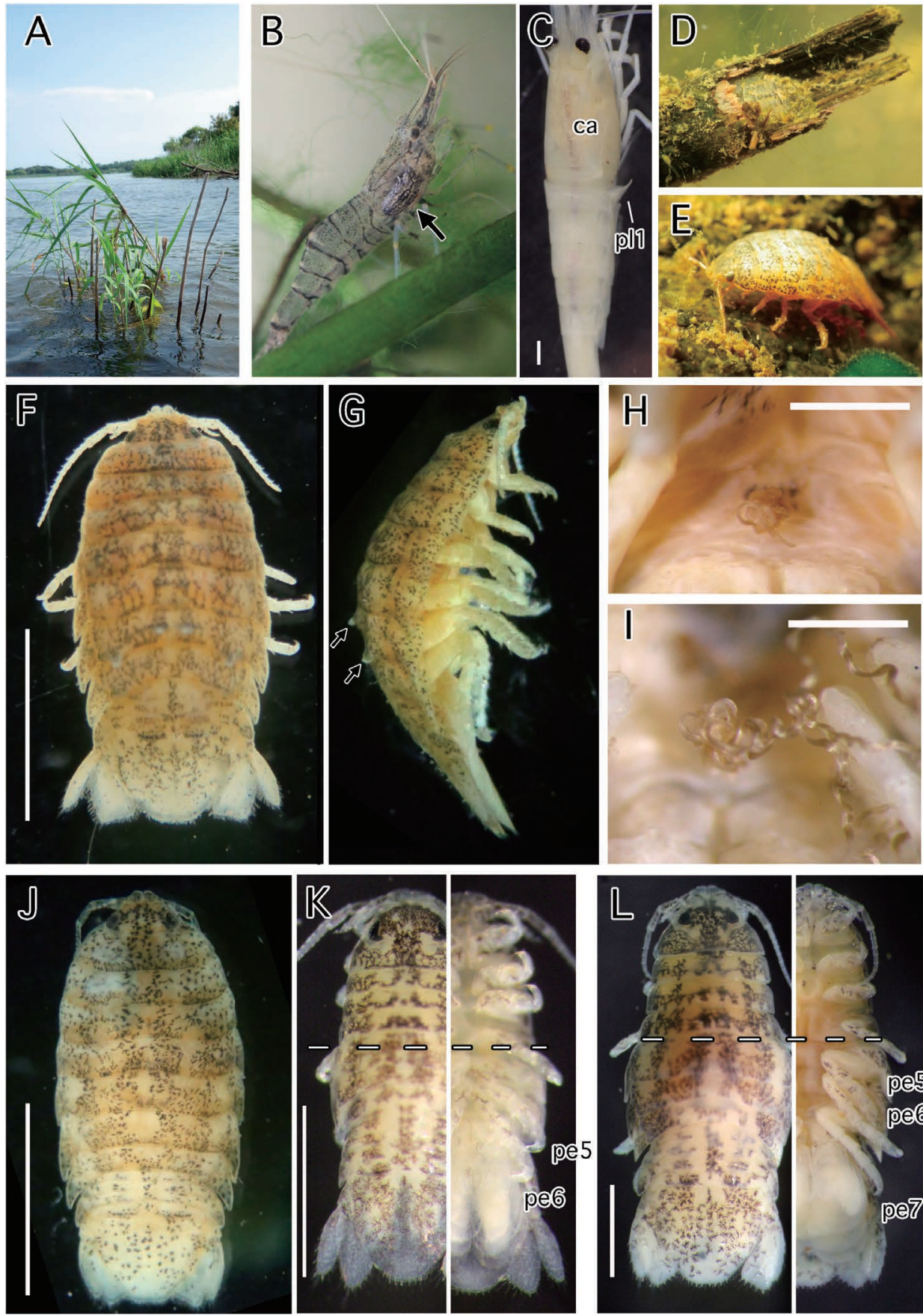

Fig. 2. Tachaea chinensis in Lake Biwa. A, Stalks of Phragmites australis; B, immature T. chinensis (arrow) parasitizing on the host shrimp Palaemon paucidens; C, pleonite 1 of a fixed host shrimp turning up laterally due to the isopods' feeding activities; D, adult $T$. chinensis dwelling in a withered stalk of $P$. australis; E, adult $T$. chinensis under a stone on the bottom; F \& G, adult male in dorsal view (F) and lateral view (G) showing two pairs of spines (arrows); H \& I, string-shaped penes; J, adult female in dorsal view, $\mathrm{K} \& \mathrm{~L}$, two phase molting (K, manca, L, immature stage). ca, carapace; pl1, pleonite 1; pe, pereopod. Scale bars $=1 \mathrm{~mm}(\mathrm{C}, \mathrm{H}, \mathrm{I}, \mathrm{K}$, and $\mathrm{L}$ ), $5 \mathrm{~mm}$ (F and $\mathrm{J})$. 
$P$. australis roots and elsewhere on the shallow creek bottom (depth $<2 \mathrm{~m}$ ) were collected while snorkeling and photographed using a waterproof digital camera (RICOH, WG-40). To check for the presence of $T$. chinensis freely swimming in the water, a plankton net $(0.5 \mathrm{~mm}$ mesh) was thrown 20 times to sample almost the entire surface area of the sampling site at 13:00 and 20:00 on 28 July 2014.

\section{Terminology of isopod stage and host identifi- cation}

In isopod crustaceans, eggs are laid in the female's brood pouch until the juveniles hatch. Juveniles are non-planktonic and have an adult-like morphology but the juveniles lack pereopod 7 (the seventh pair of walking legs). These juveniles are generally called as manca juveniles (e.g. Schram, 1986; Brusca \& Brusca, 2003; Lester, 2005). The specimens of $T$. chinensis in this study were separated into the following stages: manca juveniles, immature individuals with all seven pairs of walking legs but without fully developed penes or brood pouch, and adults. Adult males in the present samples could be distinguished from females by the two pairs of dorsal processes developed on the tergite of pereonite 6 (Fig. 2F, G) and their possession of filamentous penes (Fig. 2H, I). Female adults had no such dorsal processes (Fig. 2J) but had brood pouches formed from oostegites extending medially from the proximal parts of pereopods. The sex of immature specimens could not be determined on the basis of morphology.

Molting individuals were also counted. They were easily distinguishable because isopods usually molt in two phases. First the posterior exoskeleton between pereonite 5 and pleotelson is shed, and then, after some time, molting of the anterior exoskeleton from the head to pereonite 4 takes place. Specimens halfway through this two-part molting process thus appear to have an enlarged posterior body (Fig. $2 \mathrm{~K}, \mathrm{~L})$.
Identification of the host shrimps followed Toyota \& Seki (2014) and Tomoyuki Komai (per. com.). However, because small individuals of Neocaridina were difficult to distinguish, and Neocaridina in Japan includes alien species (Toyota \& Seki, 2014), Neocaridina species were only classified to the genus level in this paper. Voucher specimens of T. chinensis and the host shrimps have been deposited in the Lake Biwa Museum (LBM 2000012104).

\section{Results}

\section{Seasonal occurrence of host shrimps}

Monthly quadrat sampling resulted in the collection of 3,222 shrimps in total: 2,786 Neocaridina spp., 309 Paratya improvisa Kemp, 1917, 127 Palaemon paucidens, De Haan, 1844. As there were no differences in data between two quadrats, the data derived from the quadrats was combined.

The number of Neocaridina spp. increased to three maximum peaks in August $2014(\mathrm{~N}=$ 344), December $2014(\mathrm{~N}=344)$, and September $2015(\mathrm{~N}=624)$, while decreased to two minimum peaks in June $2014(\mathrm{~N}=35)$ and $2015(\mathrm{~N}=35)$ (Table 1). The number of $P$. improvisa increased to two peaks in May 2014 $(\mathrm{N}=78)$ and June $2015(\mathrm{~N}=63)$, while decreased to a minimum between August 2014 and January $2015(\mathrm{~N}=0-1)$ and between August 2015 and September $2015(\mathrm{~N}=1)$ (Table $1)$. Only one or zero individual of $P$. paucidens was collected in the monthly samples between September 2014 and March 2015, while multiple specimens $(\mathrm{N}=2-33)$ were collected between April 2014 and August 2014, and April 2014 and September 2015 (Table 1).

\section{Seasonal prevalence of Tachaea chinensis on host shrimps}

Among all the host shrimps collected using the two quadrats, 340 individuals of Neocaridina spp. (12.2\%), 17 of P. improvisa (5.5\%), and 31 of $P$. paucidens $(24.4 \%)$ were infected 


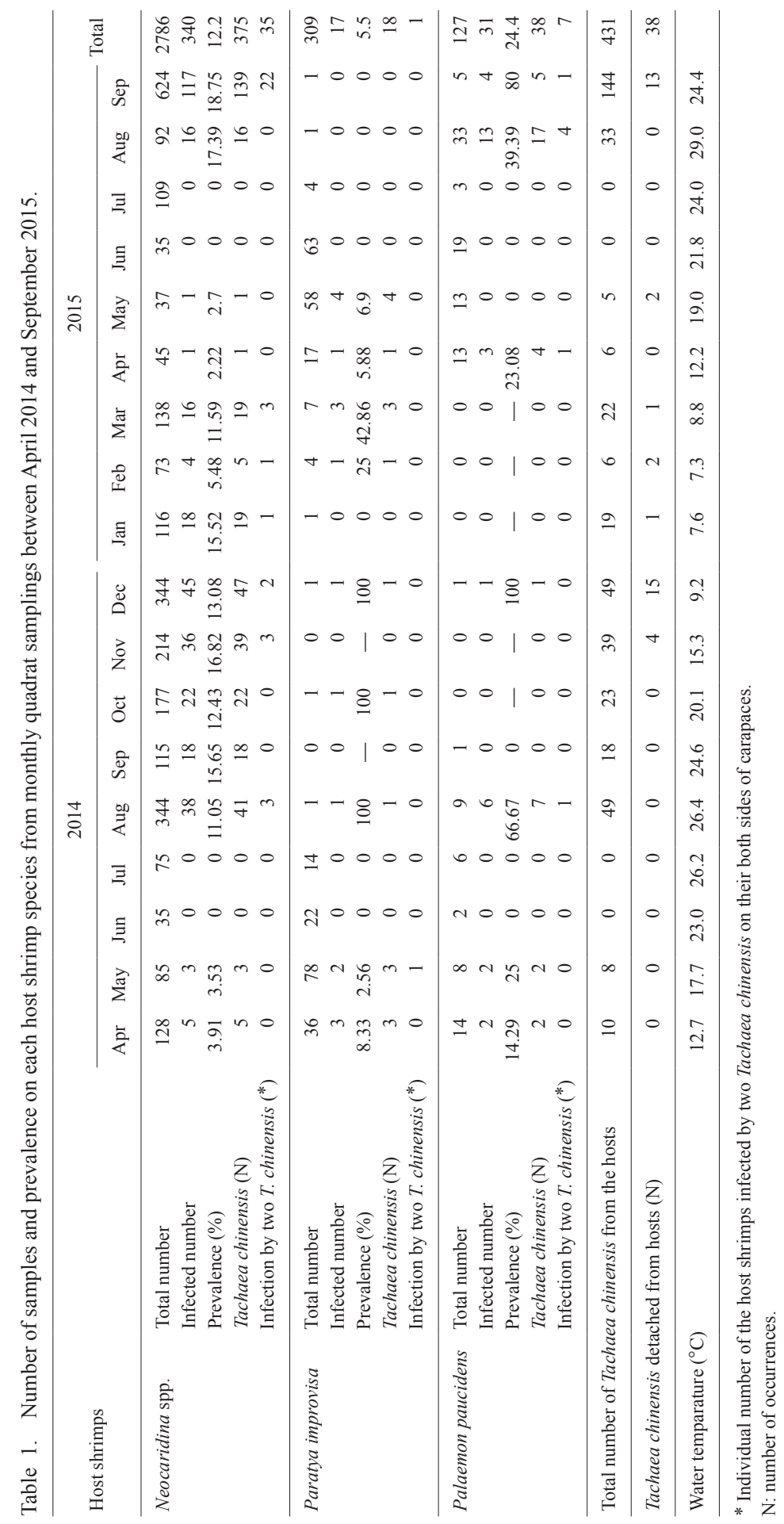




\section{by $T$. chinensis.}

Infected individuals of Tachaea chinensis were always attached to the lateral side(s) of the carapace (cephalothorax) of the host, with their heads directed posteriorly into the space between the host's carapace and pleonite 1 (Fig. 2B). Pleonite 1 (sometimes 2) of 91/385 host shrimps showed an abnormal morphology being raised laterally. This anomality may be due to the isopods' feeding activities (Fig. 2C).

One individual of $T$. chinensis usually attached to a host, but occasionally two individuals were attached to both sides of carapace of a host. This condition was found in 35 specimens of Neocaridina spp., one in P. improvisa, and seven in $P$. paucidens. Thirty-eight individuals of $T$. chinensis were detached from their hosts during the sampling process. The total number of $T$. chinensis collected during the sampling with using two quadrats was 431 .

The prevalence of T. chinensis on Neocaridina spp. was less than 5\% in April and May $2014,0 \%$ in June and July, increased to over $10 \%$ until January 2015, decreased to less than $5 \%$ between April and May, again $0 \%$ in June and July, and subsequently increased to over $10 \%$ in September 2015. Other two host shrimp species were not sufficiently sampled each month to allow a similar assessment, but the prevalence of $T$. chinensis on both of the species decreased to $0 \%$ in June and July (Table 1).

The range of body length of all $T$. chinensis from the host shrimp Neocaridina spp. in all quadrat samples was $1.8-5.8 \mathrm{~mm}$ (mean \pm standard deviation $(\mathrm{SD})=3.21 \pm 0.68, \mathrm{~N}=$ 375 ), as compared to $2.3-6.6 \mathrm{~mm}$ (mean $\pm \mathrm{SD}$ $=3.82 \pm 1.17, \mathrm{~N}=18$ ) for those from $P$. improvisa and 1.5-7.8 mm (mean $\pm \mathrm{SD}=4.04 \pm$ $1.33, \mathrm{~N}=38$ ) from $P$. paucidens. The range of body length of the host shrimp Neocaridina spp. in all quadrat samples was 6-28 mm (mean $\pm \mathrm{SD}=13.37 \pm 3.69, \mathrm{~N}=375$ ), as compared to $12-22 \mathrm{~mm}$ (mean $\pm \mathrm{SD}=17.28 \pm 3.12$, $\mathrm{N}=18$ ) for P. improvisa and 8-29 $\mathrm{mm}$ (mean

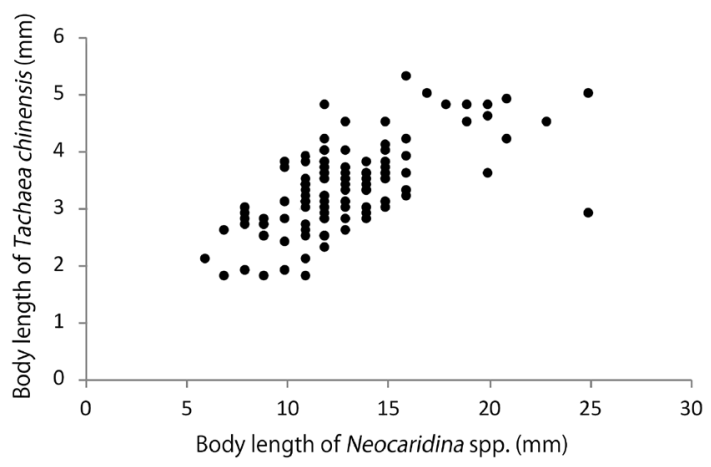

Fig. 3. Relationships of body length between host shrimps Neocaridina spp. and isopods Tachaea chinensis from quadrat samples in September 2015.

$\pm \mathrm{SD}=20.92 \pm 1.33, \mathrm{~N}=38$ ) for P. paucidens The relationship between host and isopod sizes in most months was not clear due to the insufficient sample number. Exceptionally abundant individuals were available in September 2015, and the body length of the host Neocaridina spp. and that of the isopods was positively correlated $(\mathrm{N}=139$, Pearson correlation coefficient, $r=0.63$, Fig. 3).

\section{Seasonal occurrence of Tachaea chinensis in quadrats}

No adult stages of Tachaea chinensis were collected from the three host species of Neocaridina spp., P. improvisa, and P. paucidens. Figure 4 shows size frequency distributions of T. chinensis on the basis of monthly quadrat samples. The sample number includes individuals that became detached from the hosts. After the period in June and July 2014 when $T$. chinensis were not observed on the host shrimps, manca juveniles appeared in August but were not found in September. After that, a few manca juveniles occurred in December 2014 and January 2015. Subsequently, larger and laterstage immature individuals occurred during the ensuing months until May 2015. Tachaea chinensis were not observed again on the host shrimps in June and July of 2015. Manca juveniles then reappeared on shrimps in August and September (Fig. 4). 


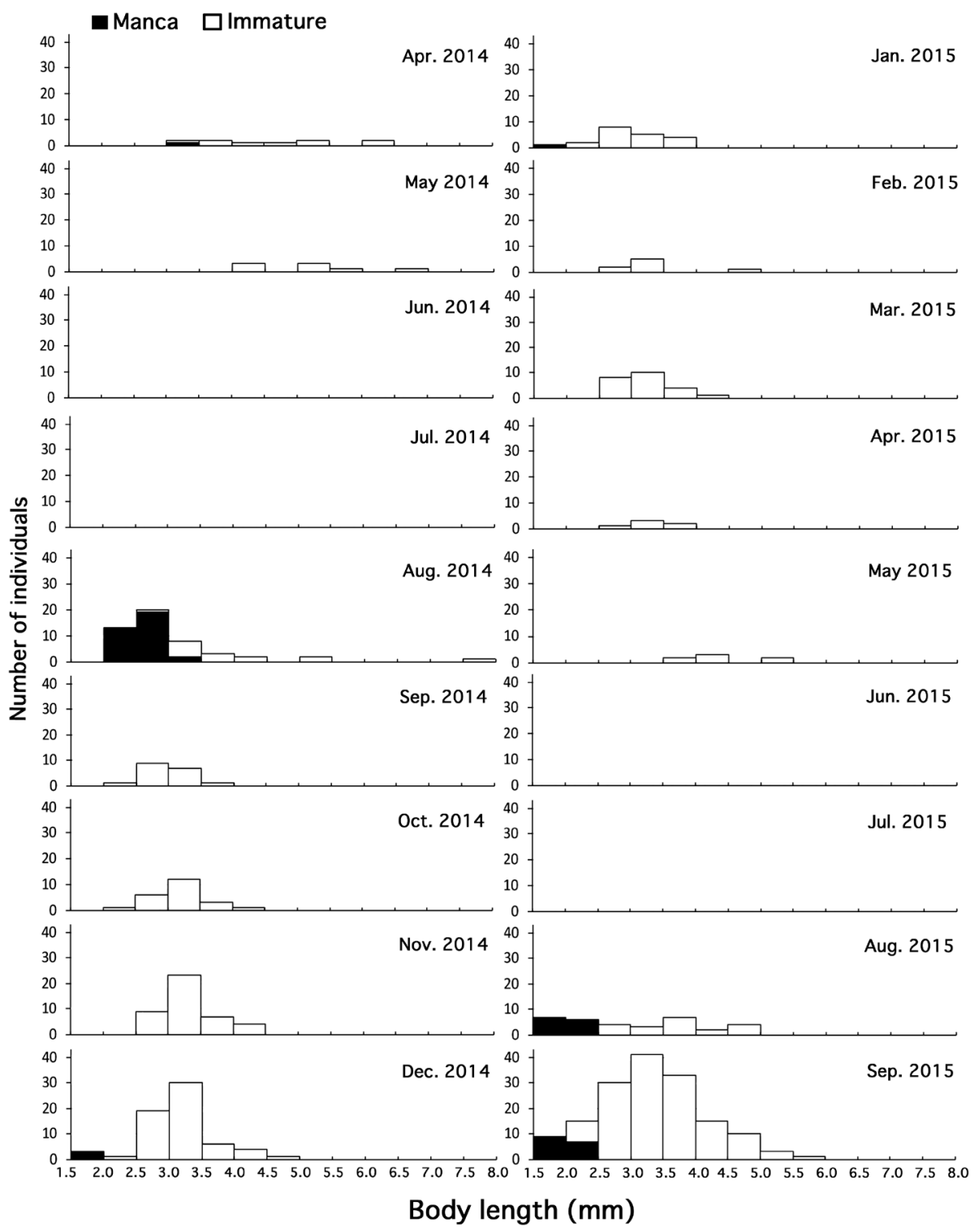

Fig. 4. Size frequency distributions of Tachaea chinensis on the basis of monthly quadrat samples.

In the quadrat sampling, molting of $T$. chinensis was observed only on Neocaridina hosts. Among the 19 posteriorly molted individuals found, five mancas all during August 2015 were observed molting into the next stage of manca on the hosts (Table 2), as shown by the continued absence of pereopod 7 after molting.
Tachaea chinensis from the phragmites trap and field observation

The phragmites trap collected 96 specimens of $T$. chinensis over the course of the study, but isopods were found in it only during July 2014 $(\mathrm{N}=6)$, July $2015(\mathrm{~N}=34)$, and September $2015(\mathrm{~N}=56)$. These isopods were large adults $(>6.0 \mathrm{~mm})$ and no small $(<6.0 \mathrm{~mm})$ isopods were collected. In July 2015, males were 7.1- 
Table 2. Collection of two-phase molts of Tachaea chinensis on Neocaridina spp.

\begin{tabular}{|c|c|c|c|}
\hline \multicolumn{2}{|c|}{ Date } & \multirow{2}{*}{$\begin{array}{c}\text { Body length }(\mathrm{mm}) \\
3.3\end{array}$} & \multirow{2}{*}{$\begin{array}{c}\text { Host body length (mm) } \\
9\end{array}$} \\
\hline 2014 & Aug & & \\
\hline \multirow[t]{18}{*}{2015} & Aug & 2.0 (manca) & 12 \\
\hline & & 2.1 (manca) & 8 \\
\hline & & 2.1 (manca) & 13 \\
\hline & & 2.0 (manca) & 9 \\
\hline & & 2.5 (manca) & 15 \\
\hline & & 4.1 & 23 \\
\hline & & 3.9 & 20 \\
\hline & Sep & 2.9 & 12 \\
\hline & & 3.9 & 11 \\
\hline & & 3.8 & 11 \\
\hline & & 3.8 & 12 \\
\hline & & 3.3 & 13 \\
\hline & & 4.5 & 23 \\
\hline & & 3.4 & 11 \\
\hline & & 3.1 & 11 \\
\hline & & 2.7 & 9 \\
\hline & & 2.8 & 13 \\
\hline & & 3.0 & 12 \\
\hline
\end{tabular}

$9.4 \mathrm{~mm}$ in body length (mean $\pm \mathrm{SD}=8.34 \pm$ $0.56, \mathrm{~N}=19$ ) and females were 7.9-10.2 mm $(8.85 \pm 0.62, \quad N=15)$. In September 2015, males were $6.0-9.5 \mathrm{~mm}(7.53 \pm 0.76, \mathrm{~N}=25)$ and females were $7.3-12.7 \mathrm{~mm}(8.68 \pm 1.00$, $\mathrm{N}=31$ ) (Fig. 5).

Female specimens in July 2015 comprised two two-phase molting females, 12 ovigerous adults, and one adult with its brood pouch empty after releasing mancas. Female specimens in September 2015 comprised three unmolted mature females, one two-phase molting females, 27 ovigerous adults, and no adult with its brood pouch empty after releasing mancas.

While snorkeling in July 2014, 29 adult $T$. chinensis were observed under stones and in withered $P$. australis roots or in cavities in withered wood. They included 12 adult males of body length $10.4 \pm 0.8 \mathrm{~mm}$ (mean \pm SD) and 17 adult females of body length $11.6 \pm 0.7 \mathrm{~mm}$. Of these 17 adult females, seven individuals had eggs in the brood pouch, three had manca juveniles, and seven had empty brood pouch

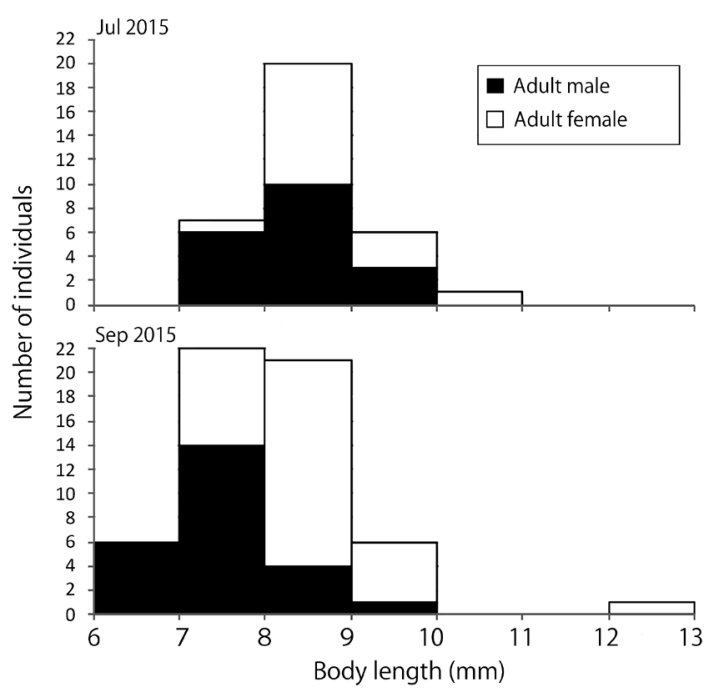

Fig. 5. Size frequency distributions of Tachaea chinensis collected by the phragmites traps in July 2015 and September 2015 .

after the manca release.

To check for the presence of manca swimming freely in the water, two subsurface samples were taken near the sampling site on 28 July 2014 with a plankton net, but no isopods were found in these samples.

\section{$\square$ Discussion}

\section{Biphasic life style of Tachaea chinensis}

Nakachi et al. (2010) briefly mentioned that Tachaea chinensis was not collected during June and July and it may breed in this season in Fukui Prefecture, northern area from this study site. Takahashi (2015) also indicated that T. chinensis was not observed on the host shrimp Paraemon paucidens from summer to early fall on the basis of monthly sampling over an annual cycle in Tokyo. The seasonal occurrence of $T$. chinensis on the hosts in this study closely corresponds with these studies.

In this study, monthly quadrat surveys of the freshwater corallanid Tachaea chinensis in the lower reaches of a Japanese creek flowing into Lake Biwa revealed that manca juveniles and small-sized immature individuals occurred on 
host shrimps except in June and July (early summer), while adults never occurred on these hosts. On the other hand, monthly trapping and random sampling while snorkeling in July uncovered both male and female adults under stones or within withered, broken plant roots in summer. Most of the adult females from these habitats were brooding embryos or mancas. It thus appears that immature stages of $T$. chinensis live as ectoparasites on host shrimp between autumn and spring, and then leave the hosts in early summer to reproduce under stones or within dead plant roots on the bottom.

Adult females are considered to release their offspring as manca juveniles in summer, because some females were bearing eggs or mancas at this time, while others were spent, with empty brood pouches. Plankton sampling in this season, albeit limited in scope, did not sample any manca juveniles, while the number of mancas recovered from host shrimps increased from August to September. This implies that the mancas attach to host shrimps soon after release from the brood chamber and may not actively swim for any extended period of time.

\section{Development of Tachaea chinensis on hosts}

The number of manca stages in most isopods is three (Boyko and Wolff, 2014), however, the number of developmental stages in the life cycle of Tachaea chinensis remains unclear. There are at least two manca stages because, some mancas from quadrat samples were observed to molt into the next manca stage, which was still characterized by the absence of pereopod 7 after the molting of the posterior portion of the cuticle (Fig. 2K). Mancas molting into the next stage were collected from host shrimps and almost no small-sized immature individuals were collected away from the hosts in this study. This indicates that young T. chinensis molt on the hosts.

In the quadrat samples, most of $T$. chinensis were small $(<6 \mathrm{~mm})$ in body length; four larg- er-sized individuals were included in a total of 431 individuals. Small T. chinensis mainly infected Neocaridina spp., while both small and large $T$. chinensis were collected from two other hosts, Paratya improvisa and Palaemon paucidens. Body length of $P$. improvisa and $P$. paucidens grow up to approximately $31 \mathrm{~mm}$ and $63 \mathrm{~mm}$, respectively (Toyota and Seki, 2014). Neocaridina spp. reached a maximum of $25 \mathrm{~mm}$ in body length, while $P$. paucidens and $P$. improvisa grew larger. Tachaea chinensis was always attached to the lateral side of its host's carapace, a region that in Neocaridina spp. does not provide enough space for a large isopod to attach.

\section{Comparison with other corallanid isopods' lifestyles}

As for other corallanid isopods, there are only a few studies available for understanding their lifestyle such as host/food and habitat utilization. On the basis of plankton samples, Guzman et al. (1988) studied ecological aspects of the marine corallanid Excorallana tricornis occidentalis Richardson, 1905 off the Pacific coast of Costa Rica. This species is nocturnal and preys on zooplankton. It is not parasitic. Because plankton nets rarely collected ovigerous females, these authors concluded that ovigerous females might be hiding in the substrate. Guzman et al. (1988) also showed that the density of E. tricornis occidentalis peaked around midnight, with the highest nighttime density occurring between November and January (fall and winter seasons). The largest percentages of juveniles occurred in July and November, a probable indication of spring and fall recruitment bursts.

In contrast to E. tricornis occidentalis, the developmental stages (manca and immature stages) of $T$. chinensis always attach to host shrimps. Sometimes detached T. chinensis away from the host was collected from the quadrat samples in this study. Shen (1936) and Takahashi (2015) reported detached individuals 
of $T$. chinensis have been observed to swim in the water. However, such individuals may not have been free-swimming but accidentally detached from the hosts because young $T$. chinensis were rarely collected from the bottom (just one case, in April 2014) in this study. Even molting individuals were collected from host shrimp. The young $T$. chinensis are thus not temporary or opportunistic parasites of shrimps but able to parasitize them over extended periods, although I have no information as to the length of time spent on one individual host before moving to another.

Delaney (1989) reviewed that corallanid species are often found on or in corals, calcareous sponges, ascidians, bryozoans, gorgonians, coralline algae, tubeworms, scyphozoans, and tube-building snails. On the other hand, they emerge from these cryptic habitats and from "commensal" associations to temporarily parasitize or prey on fish, rays, shrimp, and turtles, as well as to prey on mysids. Focusing on $E$. tricornis occidentalis, Guzman et al. (1988) concluded that the juveniles, males, and females might prey on mysids but ovigerous females remain hidden in the substrate while brooding embryos and mancas. This species has been recorded as a commensal in sponges (Richardson, 1905; Delaney, 1984) and in mangrove habitats (Monod, 1969), and it associated with hydrozoans on andesitic rock (Delaney, 1984). Thus, corallanid isopods would feed on prey or parasitize hosts during immature stages and utilize substrate to hide and reproduce in mature stages.

\section{$\square$ Conclusion}

This paper provides fundamental information necessary for understanding the ecology of Tachaea chinensis and for demonstrating its biphasic life history with parasitic juveniles and free-living adults. However, an insufficient number of large-sized $(>6 \mathrm{~mm})$ specimens of $T$. chinensis were collected from the main host shrimp Neocaridina spp. Detailed information of lager-sized T. chinensis infesting on Palaemon paucidens and Paratya improvisa in Lake Biwa remains unclear. For a more complete picture, additional surveys at other sampling sites and/or involving other host shrimp species are necessary.

\section{Acknowledgments}

I would like to thank Dr. Shigefumi Kanao (Lake Biwa Museum) for valuable comments and literature, and Dr. Tomoyuki Komai (Natural History Museum and Institute, Chiba) for help in identifying the shrimps. This study was partly done during my term of appointment as a Special Researcher at the Lake Biwa Museum; I would like to thank Dr. Mark J. Grygier (formerly at the Lake Biwa Museum, currently at the National Taiwan Ocean University) for hosting me then, and for commenting on an earlier draft of this paper. Dr. Katsuhiko Tanaka (Tokai University) provided valuable comments for improving the manuscript.

\section{Literature Cited}

Boyko, C. B., \& Wolff C., 2014. Isopoda and Tanaidacea. In: Martin, J. W., Olesen, J. \& Høeg J. T. (ed), Atlas of Crustacean Larvae. Johns Hopkins University Press, Maryland, pp. 210-215.

Bruce, N. L., \& Schotte, M., 2015. Corallanidae Hansen, 1890. In: Boyko, C. B., Bruce, N. L., Hadfield, K. A., Merrin, K. L., Ota, Y., Poore, G. C. B., Taiti, S., Schotte, M., \& Wilson, G. D. F. (Eds) (2008 onwards). World Marine, Freshwater and Terrestrial Isopod Crustaceans database. Accessed through: World Register of Marine Species at http://www.marinespe cies.org/aphia.php? $\mathrm{p}=$ taxdetails\&id $=196132$, accessed on 2017-12-11.

Brusca, C. B., \& Brusca, G. J., 2003. Invertebrates. Second edition. 936 pp. Sinauer Associates, Sunderland, Massachusetts. 
Delaney, P. M., 1984. Isopods of the genus Excorallana Stebbing, 1904 from the Gulf of California, Mexico (Crustacea, Isopoda, Corallanidae). Bulletin of Marine Science, 34(1): 1-20.

Delaney, P. M., 1989. Phylogeny and biogeography of the marine isopod family Corallanidae (Crustacea, Isopoda, Flabellifera). Natural History Museum of Los Angeles County, Contributions in Science, 409: 1-75.

Guzman, H. M., Obando, V. L., Brusca, R. C., \& Delaney, P. M., 1988. Aspects of the population biology of the marine isopod Excorallana tricornis occidentallis Richardson, 1905 (Crustacea: Isopoda: Corallanidae) at Cano Island, Pacific Costa Rica. Bulletin of Marine Science, 43(1): 77-87.

Hayashi, M., 2011. Record of Tachaea chinensis Thielemann (Isopoda, Corallanidae) from Kozakai-cho, Izumo-shi, Shimane Prefecture, Japan. Bulletin of the Hoshizaki Green Foundation, 14: 294. [In Japanese with English title]

Lester, R. J. G., 2005. Isopoda (isopods). In: Rohde, K. (ed), Marine Parasitology. CSIRO Publishing, Collingwood, pp. 138-144.

Monod, T., 1969. Sur trois crustacés isopodes marins de la région Guyane-Amazone. Cahiers. Orstom, Série Océanographie, 7: 4768.

Nagasawa, K., Imai, T., \& Saito, H., 2018. Tachaea chinensis (Isopoda: Corallanidae), an ectoparasite of freshwater shrimps and prawns, from western Japan, with a list of its known collection localities and hosts. Crustacean Research, 47: 73-88.

Nakachi, Y., Shimizu, T., Nogami, N., \& Makita, S., 2010. [Studies on Tachaea chinensis II. Blood sucking behavior of $T$. chinensis]. Umiushi Tsushin, 66: 10. [In Japanese]
Richardson, H. R., 1905. A monograph of the isopods of North America. Bulletin of United States National Museum, 54: 1-727.

Schram, F. R., 1986. Crustacea. 620 pp. Oxford University Press, New York.

Shen, C.-J., 1936. The fresh-water isopods of Peiping. Bulletin of the Fan Memorial Institute of Biology (Zoology), 7: 1-31.

Shiino, S., 1965. Tachea [sic] chinensis Thielemann. In Y. Okada, S, Uchida, \& T., Uchida (eds.), New Illustrated Encyclopedia of the Fauna of Japan (II). Hokuryukan, Tokyo, p. 542, unnumbered fig. [In Japanese]

Takahashi, J., 2015. Parasitization rate and its seasonal fluctuation of Tachea [sic] chinensis in Paraemon [sic] pausidens. Animate, 12: 20-23. [In Japanese with English title]

Takeda, M., Shimazu, T., Urawa, S., Araki, J., Kuramochi, T., \& Machida, M., 2000. Ectoparasite crustaceans of shrimps and fishes from the inside moats of the Imperial Palace, Tokyo (in Japanese with English summary). Memoirs of the National Science Museum, Tokyo, 35: 75-78.

Thielemann, M., 1910. Beiträge zur Kenntnis der Isopodenfauna Ostasiens. Abhandlungen der mathematisch-physikalischen Klasse der Koeniglich-Bayerische Akademie der Wissenschaften, Supplementary Volume, 2: 1-109.

Toyota, K., \& Seki, S., 2014. [Freshwater Shrimps and Crabs of Japan: 102 species from Fresh and Brackish Waters]. $255 \mathrm{pp}$. Seibundo Shinokosha, Tokyo. [In Japanese]

\section{Address}

YO (Corresponding Author)

San' in Kaigan Geopark Museum of the Earth and Sea, 1794-4, Makidani, Iwami-cho, Tottori 681-0001, Japan.

E-mail: yota1164@gmail.com 